\title{
Wind resource assessment and wind power potential for the city of Ardabil, Iran
}

\author{
Farivar Fazelpour • Nima Soltani • Marc A. Rosen
}

Received: 27 June 2014/ Accepted: 20 August 2014/Published online: 20 September 2014

(C) The Author(s) 2014. This article is published with open access at Springerlink.com

\begin{abstract}
The results of an investigation of the potential of wind energy as a power source are reported for an Iranian north-western city, Ardabil. The Weibull probability distribution function using a long-term data source, consisting of 6 years (2005-2010) of 3-h period measured mean wind data, is adopted and analyzed. The data have been measured at a height of $10 \mathrm{~m}$ above the ground level. Also, monthly and annual wind speed variations are analyzed. The monthly mean wind speed is between 2.09 and $6.58 \mathrm{~m} / \mathrm{s}$, while the annual mean wind speed is in the range of $3.28-4.08 \mathrm{~m} / \mathrm{s}$. The Ardabil site is found to have good characteristics from the perspective of mean wind speed. The numerical values of the shape and scale parameters for Ardabil are seen to vary over a wide range. The monthly mean value of shape parameter $(k)$ is between 2.62 and 3.17 , while the monthly mean value of the Weibull scale parameter $(c)$ is between 3.36 and $5.43 \mathrm{~m} / \mathrm{s}$. The results show that the months of October and September have higher mean power densities and that July has a lower mean power density than other months. Also, the wind potential of the studied region is determined to be very suitable for the off-grid connections and could be acceptable for connecting to power grids.
\end{abstract}

Keywords Clean energy - Mean wind speed · Power density $\cdot$ Wind potential $\cdot$ Weibull parameters

F. Fazelpour · N. Soltani $(\bowtie)$

Department of Energy Systems Engineering,

Faculty of Engineering, Islamic Azad University-South

Tehran Branch, Tehran, Iran

e-mail: nima_soltani@yahoo.com

M. A. Rosen

Faculty of Engineering and Applied Science, University

of Ontario Institute of Technology, Oshawa, ON, Canada

\section{Introduction}

In recent years the world's population growth and other factors have led to daily increasing energy consumption. Also, constraints regarding fossil fuels, the main energy source around the world, such as environmental impacts as climate change and droughts, and rising fossil fuel prices, have caused researchers to consider alternative energy sources. Renewable energy is often viewed as a good option because it is widely available and environmentally friendly. Experience using renewable energy sources, especially wind since 1970, and energy crises has contributed further to growing interest [1]. Wind energy is becoming quite popular compared to other renewable energy sources such as solar, biomass, tidal and wave [2]. Approximately, 10 million MW of wind energy is continuously available on the Earth [3]. The European Wind Energy Union classifies wind energy as follows [4]:

- Nearly $\operatorname{good}(\bar{V}=6.5 \mathrm{~m} / \mathrm{s})$

- $\operatorname{Good}(\bar{V}=7.5 \mathrm{~m} / \mathrm{s})$

- $\operatorname{Very} \operatorname{good}(\bar{V}=8.5 \mathrm{~m} / \mathrm{s})$

where $\bar{V}$ denotes the mean wind speed at a given height.

In Fig. 1 (Data source [5]), the global annual installed wind capacity from 1996 to the end of 2012 is shown. The capacity increased for 1996-2012 and increased more than four times from 2006 to 2012. During 2010, global wind power capacity increased by $24 \%$ relative to 2009 , an annual increase rate higher than for most other renewable technologies. In 2012, 44.7 GW of wind power capacity was operational and the annual increase was approximately $19 \%$.

In 1990, the global capacity of wind turbine generators connected to the grid was around 2,000 MW, mainly in the 
Fig. 1 Global annual installed wind power generation capacity for 1996-2012. Data source [5]

Fig. 2 Annual installed wind generation capacity by region for 2004-2012. Data source [5]
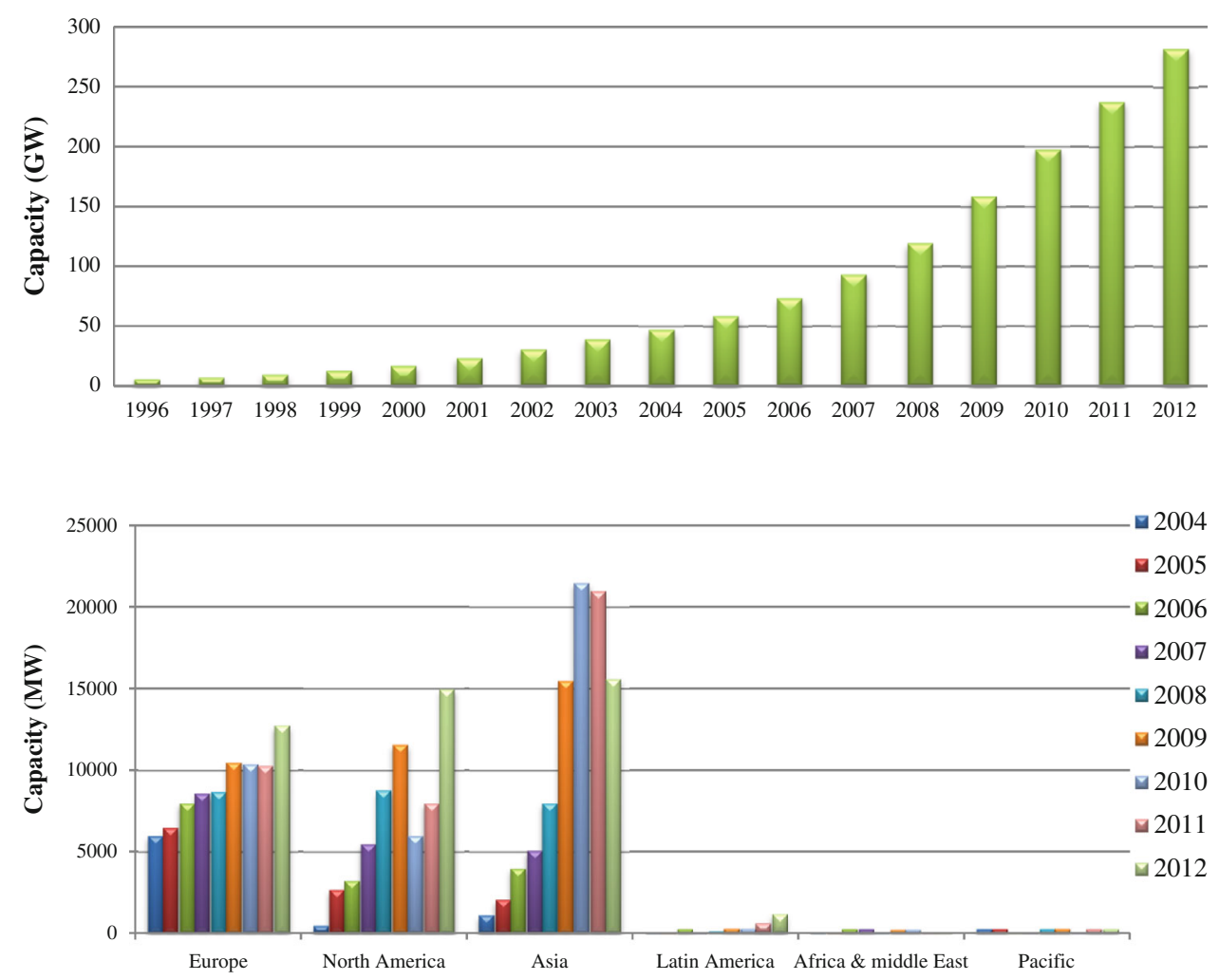

USA and Denmark [6]. At that time, the Netherlands, Germany, England, Italy and India began to use wind energy [6]. With technology advances, the cost of energy produced by wind turbines declined, but the overall use of wind power generation systems is still relatively small.

The use of wind energy from 2004 to 2012 is shown in Fig. 2 for six regions of the world (Data source [5]). Since 2009, the Asian continent surpassed the North America and European continents. In 2012, China and India were responsible for 27 and $6 \%$, respectively, of wind energy use, i.e., the first and fifth highest. The USA and Canada are responsible for 21 and $2 \%$, respectively, and are the second and ninth largest wind energy users globally, while Germany and Spain account for 11 and $8 \%$, respectively, representing the third and fourth highest [5].

Many studies have been conducted using Pearson, Johnson, log-normal, Weibull, Rayleigh and Gaussian distributions [7]. The Weibull distribution function has been shown to have advantages over other distribution functions [8], including flexibility, simplicity and the ability to accommodate a wide range of data [9]. In recent years, much research on the assessment of wind energy potential has been performed around the word, with many of these investigations using wind data obtained at a height of $10 \mathrm{~m}$ aboveground level.

Sahin et al. [10] showed that the wind resource for the east Mediterranean was excellent for power generation and that the area was suitable for private sector investment. In 2010, a wind potential assessment based on the Weibull model was performed for the capital of Iran, Tehran, for 11 years (1995-2005) and concluded that the wind energy potential was promising, especially in March, April and May [11]. In 2011, a study of the wind potential for three areas of Turkey (Mediterranean, West Black Sea and interior Aegean regions) determined that these regions have very good wind potential for electricity generation [12].

Mostafaeipour et al. [13] studied the Binalood region in Iran in 2013 using measured wind speed data for 2007-2010 at 10, 30 and $40 \mathrm{~m}$ heights, and showed that the long-term wind speeds were sufficiently high to provide a good wind energy potential for grid connection systems. Other studies related to Iran include investigations of the potential for offshore wind turbines in Iran, a comparison with the world [14] and the future of renewable energies in Iran [15], and a comparison of renewable energy issues in the Middle East and Iran [16].

In 2007, an investigation was performed of the wind potential of the Manjil area, a potentially advantageous region to install wind turbines in Iran and around the world. It was demonstrated that the growth of investment and installation of more wind turbines had increased the share of wind energy use in Iran and had been very important to the region's economic development [17]. Saeidi et al. [18] 
investigated in 2011 wind resources at the northern and southern Khorasan Province of Iran, using the Weibull model, and showed that the wind resources in Bojnourd, Esfarayen and Nehbandan were appropriate for both ongrid and stand-alone activities. In 2011, a feasibility study using the Weibull model was performed on employing wind energy for the city of Babak, Iran, and showed that small wind turbine projects were feasible for supplying electricity to homes at the site. Also, the study site is suitable for off-grid applications [19]. Jie et al. [20] assessed the available wind energy potential in Inner Mongolian China using Weibull, logistic and log-normal parameters, measured data for the years 2009-2011 and showed that it was advantageous to build a wind farm in this region.

In this study, we determine the wind energy potential in the northwestern Iranian city of Ardabil. The objective is to improve the understanding of potential uses of wind energy. The Weibull probability distribution function is employed using a long-term data source consisting of 6 years (2005-2010) of 3-h period measured mean wind data, taken at a height of $10 \mathrm{~m}$ aboveground level. Monthly and annual wind speed variations are analyzed, and the Weibull distribution, the wind power density and the wind energy density are determined.

\section{Data collection and site description}

Ardabil $\left(38^{\circ} 15^{\prime} \mathrm{N} 48^{\circ} 17^{\prime} \mathrm{E}\right)$, the center of Ardabil Province, is a historical city in northwest Iran. Ardabil has an average altitude of $1,350 \mathrm{~m}$ and a total area of $110.81 \mathrm{~km}^{2}$. At the 2011 census, its population was 482,600. It is located about $70 \mathrm{~km}$ from the Caspian Sea, $210 \mathrm{~km}$ from the city of Tabriz, $600 \mathrm{~km}$ from Tehran and near the border with Azerbaijan. The city has political and economic importance. Ardabil's climate is cold and semiarid, with many people coming to this region for its relatively cool climate during the summer. Winters in Ardabil are long and cold, with temperatures as low as $-27{ }^{\circ} \mathrm{C}$. Climate data for Ardabil are shown in Table 1 (Data source [21]).

\section{Analysis procedure}

Weibull probability density function

Wind speed is a random quantity. The most common density function utilized to characterize wind speed is the Weibull probability density function $f(v)$ [22]:

$f(v)=\frac{k}{c}\left(\frac{v}{c}\right)^{k-1} \exp \left(-\left(\frac{v}{c}\right)^{k}\right), k>0, v>0, c>1$

Here, $v$ denotes the wind speed, $k$ the shape factor (dimensionless) and $c$ the scale factor $(\mathrm{m} / \mathrm{s})$. As the names suggest, $k$ determines the shape of the distribution curve and $c$ the scale. Empirically, it has been observed that wind speed in most locations follows a Weibull distribution.

The following approximation can be used for the Weibull parameter $k$ [23]:

$k=\left(\frac{\sigma}{\bar{v}}\right)^{-1.086}$

which is valid when $1 \leq k \leq 10$. The value of $k$ is approximately 2 for most wind profiles. Also, the following approximation can be used for the Weibull parameter $c$ [24]:

$c=\frac{\bar{v}}{\Gamma\left(1+\frac{1}{k}\right)}$

where $\bar{v}$ denotes the mean wind speed, which can be calculated as follows:

$\bar{v}=\frac{1}{n} \sum_{i=1}^{n} v_{i}$

The term $\sigma^{2}$ represents the variance for wind velocity measurements, and can be calculated as follows:

$\sigma^{2}=\frac{1}{n-1} \sum_{i=1}^{n}\left(v_{i}-\bar{v}\right)^{2}$

The average wind speed and the variance of wind velocity can be calculated on the basis of the Weibull parameters as follows [25]:

Table 1 Climate data for Ardabil

\begin{tabular}{|c|c|c|c|c|c|c|c|c|c|c|c|c|c|}
\hline Month & Jan & Feb & Mar & Apr & May & Jun & Jul & Aug & Sep & Oct & Nov & Dec & Year \\
\hline Average high $\left({ }^{\circ} \mathrm{C}\right)$ & 3.0 & 4.5 & 9.3 & 16.7 & 19.7 & 23.2 & 25.0 & 24.7 & 22.6 & 17.5 & 11.4 & 5.7 & 15.28 \\
\hline Average low $\left({ }^{\circ} \mathrm{C}\right)$ & -7.9 & -6.3 & -2.4 & 2.8 & 6.0 & 9.0 & 11.6 & 11.6 & 8.7 & 4.8 & 0.3 & -4.6 & 2.8 \\
\hline Precipitation (mm) & 24.7 & 21.8 & 37.4 & 38.3 & 45.1 & 19.4 & 6.7 & 5.4 & 9.9 & 33.0 & 37.1 & 25.1 & 303.9 \\
\hline Average precipitation days (mm) & 8.0 & 8.5 & 11.2 & 11.5 & 13.7 & 6.9 & 3.9 & 3.8 & 5.8 & 8.8 & 7.5 & 7.7 & 97.3 \\
\hline
\end{tabular}

Data source [21] 
$\bar{v}=c \Gamma\left(1+\frac{1}{k}\right)$

$\sigma^{2}=c^{2}\left[\Gamma\left(1+\frac{2}{k}\right)-\Gamma^{2}\left(1+\frac{2}{k}\right)\right]$

where the gamma function of $(x)$ (standard formula) is calculated as:

$\Gamma(x)=\int_{0}^{\infty} e^{-u} u^{x-1} \mathrm{~d} u$

The main limitation of the Weibull density function is that it does not accurately represent the probabilities of observing zero or very low wind speeds. However, for estimating the wind potential for commercial use of wind turbines, this is usually unnecessary as the energies at low wind speeds are small (wind energy is proportional to the cube of wind speed) and below the operating range of wind turbines (i.e., the cut-in wind speed is usually $2.5-3.5 \mathrm{~m} / \mathrm{s}$ ).

Wind power density

To understand the impact on power generation of the statistical distribution of wind speed, consider its impact on power density. Wind power density is defined as:

$P(v)=\frac{1}{2} \rho v^{3}$

where $\rho$ is the standard air density at sea level with a mean temperature of $15{ }^{\circ} \mathrm{C}$ and a pressure of $1 \mathrm{~atm}(1.225 \mathrm{~kg} /$ $\left.\mathrm{m}^{3}\right)$ and $v$ is the mean wind speed $(\mathrm{m} / \mathrm{s})$. Also, the corrected monthly air density $\rho\left(\mathrm{kg} / \mathrm{m}^{3}\right)$ is calculated as follows:

$\rho=\frac{\bar{P}}{R_{\mathrm{d}} \bar{T}}$

where $\bar{P}$ is the monthly average air pressure, $\bar{T}$ is the monthly average air temperature $(\mathrm{K})$ and $R_{\mathrm{d}}$ is the gas constant for dry air $(287 \mathrm{~J} / \mathrm{kg} \mathrm{K})$.

The corrected wind power available at a height of $10 \mathrm{~m}$ can be calculated as follows [26]:

$P_{10}=\frac{1}{2} \overline{\rho v}^{3}$

The monthly corrected and uncorrected wind power values reveal that the corrected air density values are almost stable. Also, the shift from standard air density $(\rho)$ is very small for the selected region, so the latter value is considered in the present study. Wind power estimates are based on the assumption that the air density is not correlated with wind speed, and the error introduced by this assumption on a constant pressure surface is less than $5 \%$.

Wind power density $\left(\mathrm{W} / \mathrm{m}^{2}\right)$ takes into account the frequency distribution of the wind speed and the dependence of wind power on air density and the cube of the wind speed. Therefore, wind power density is generally considered a better indicator of the wind resource than wind speed. The average wind power density in terms of wind speed can be calculated as:

$\mathrm{WPD}=\frac{\sum_{i=1}^{N} \frac{1}{2} \rho v_{i}^{3}}{N}$

Here, $i$ is the measured three-hourly wind speed and $N$ is the total sample data used for each year. Also, the wind power density, or $P / A$, can be evaluated with the Weibull distribution as

$\frac{P}{A}=\int_{0}^{\infty} \frac{1}{2} \rho v^{3} f(v) \mathrm{d} V=\frac{1}{2} \rho c^{3} \Gamma\left(\frac{k+3}{k}\right)$

Wind energy density

Once wind power density of a site is known, the wind energy density for a desired duration $T$ can be calculated as

$\frac{E}{A}=\frac{1}{2} \rho c^{3} \Gamma\left(\frac{k+3}{k}\right) T$

This equation can be used to calculate the available wind energy for any defined period of time when the wind speed frequency distributions are for a different period of time. The Betz limit for wind rotors in idealized conditions indicates that they can extract, at most, $59.3 \%$ of energy in the wind. Therefore, the maximum extractable power from the wind is the product of the factor 0.593 and the calculated result from Eq. (13), i.e., $P_{\text {Betz }}=$ $0.593 P_{\text {ideal }}$.

Most probable wind speed

The most probable wind speed $V_{\mathrm{mp}}(\mathrm{m} / \mathrm{s})$ can be determined using the Weibull parameters $k$ and $c$. The most probable wind speed is the most frequent wind speed for a given wind probability distribution and can be expressed as follows [25]:

$V_{\mathrm{mp}}=c\left(1-\frac{1}{k}\right)^{\frac{1}{k}}$

Wind speed with maximum energy

The wind speed with the maximum energy, $V_{\max , \mathrm{E}}$, can be determined using the Weibull parameters $k$ and $c$ as follows [25]:

$V_{\max , \mathrm{E}}=c\left(1-\frac{2}{k}\right)^{\frac{1}{k}}$ 
Table 2 Yearly and monthly wind speed means and standard deviations (in m/s) for Ardabil for $2005-2010$

\begin{tabular}{|c|c|c|c|c|c|c|c|c|}
\hline Month & Parameter & 2005 & 2006 & 2007 & 2008 & 2009 & 2010 & 2005-2010 \\
\hline \multirow[t]{2}{*}{ January } & $\bar{v}$ & 3.06 & 3.67 & 6.22 & 2.91 & 3.52 & 6.37 & 4.29 \\
\hline & $\sigma$ & 1.26 & 1.40 & 2.84 & 1.28 & 1.43 & 2.41 & 1.77 \\
\hline \multirow[t]{2}{*}{ February } & $\bar{v}$ & 4.39 & 6.58 & 4.44 & 3.52 & 4.59 & 5.66 & 4.86 \\
\hline & $\sigma$ & 1.43 & 2.29 & 1.71 & 1.19 & 1.69 & 1.78 & 1.68 \\
\hline \multirow[t]{2}{*}{ March } & $\bar{v}$ & 5.05 & 3.93 & 3.67 & 5.10 & 5.56 & 6.02 & 4.88 \\
\hline & $\sigma$ & 2.04 & 1.16 & 1.14 & 1.98 & 2.23 & 2.15 & 1.78 \\
\hline \multirow[t]{2}{*}{ April } & $\bar{v}$ & 3.72 & 3.62 & 4.28 & 3.01 & 4.13 & 3.82 & 3.76 \\
\hline & $\sigma$ & 1.20 & 1.11 & 1.51 & 1.33 & 2.13 & 1.27 & 1.42 \\
\hline \multirow[t]{2}{*}{ May } & $\bar{v}$ & 2.80 & 3.21 & 2.91 & 2.80 & 3.26 & 2.96 & 2.99 \\
\hline & $\sigma$ & 1.04 & 1.28 & 1.15 & 1.12 & 1.34 & 1.26 & 1.20 \\
\hline \multirow[t]{2}{*}{ June } & $\bar{v}$ & 3.31 & 3.37 & 2.91 & 3.42 & 3.26 & 2.91 & 3.20 \\
\hline & $\sigma$ & 1.05 & 1.09 & 1.19 & 1.23 & 1.08 & 1.15 & 1.13 \\
\hline \multirow[t]{2}{*}{ July } & $\bar{v}$ & 3.26 & 4.08 & 4.03 & 3.52 & 4.08 & 4.28 & 3.88 \\
\hline & $\sigma$ & 1.19 & 1.54 & 1.42 & 1.12 & 1.26 & 1.92 & 1.41 \\
\hline \multirow[t]{2}{*}{ August } & $\bar{v}$ & 3.82 & 3.06 & 3.21 & 3.57 & 4.18 & 3.67 & 3.59 \\
\hline & $\sigma$ & 1.43 & 1.30 & 1.75 & 1.32 & 1.61 & 1.22 & 1.44 \\
\hline \multirow[t]{2}{*}{ September } & $\bar{v}$ & 3.06 & 3.31 & 3.42 & 3.01 & 3.01 & 3.47 & 3.21 \\
\hline & $\sigma$ & 1.11 & 1.21 & 1.07 & 1.30 & 1.28 & 1.26 & 1.20 \\
\hline \multirow[t]{2}{*}{ October } & $\bar{v}$ & 3.16 & 3.57 & 2.70 & 2.80 & 2.80 & 3.62 & 3.11 \\
\hline & $\sigma$ & 1.16 & 1.05 & 1.22 & 1.01 & 1.20 & 1.39 & 1.17 \\
\hline \multirow[t]{2}{*}{ November } & $\bar{v}$ & 2.40 & 4.28 & 4.49 & 2.86 & 3.72 & 2.09 & 3.31 \\
\hline & $\sigma$ & 1.01 & 1.89 & 1.96 & 1.00 & 1.20 & 1.06 & 1.35 \\
\hline \multirow[t]{2}{*}{ December } & $\bar{v}$ & 3.26 & 2.55 & 3.11 & 2.91 & 5.05 & 3.82 & 3.45 \\
\hline & $\sigma$ & 1.21 & 1.21 & 1.29 & 1.03 & 1.37 & 1.12 & 1.20 \\
\hline \multirow[t]{2}{*}{ Year } & $\bar{v}$ & 3.44 & 3.77 & 3.78 & 3.28 & 3.93 & 4.06 & 3.71 \\
\hline & $\sigma$ & 1.32 & 1.38 & 1.52 & 1.24 & 1.48 & 1.50 & 1.41 \\
\hline
\end{tabular}

\section{Results and discussion}

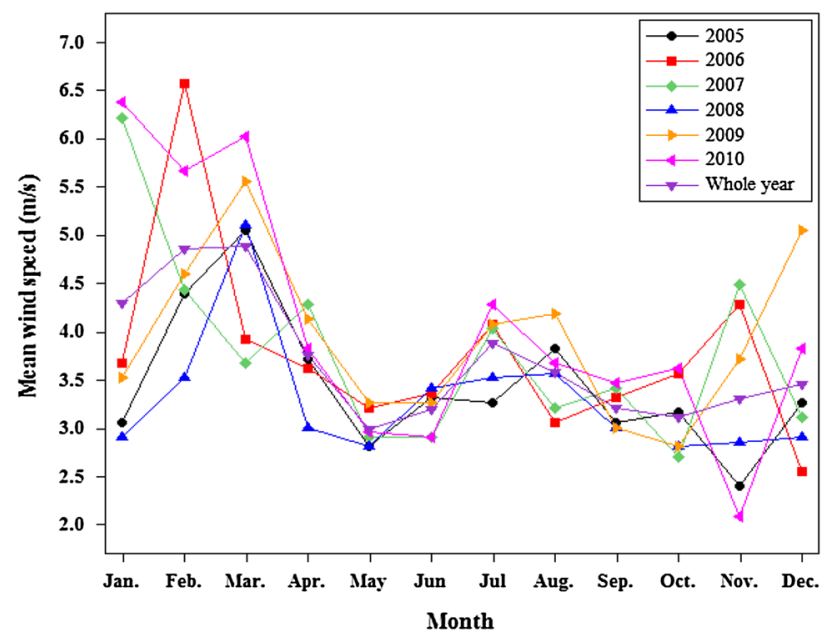

Fig. 3 Monthly mean wind speeds at $10 \mathrm{~m}$ elevation for Ardabil for 2005-2010
In this study, wind speed data obtained for Ardabil, Iran, over the 6-year period 2005-2010 are analyzed, and the Weibull distribution parameters $c$ and $k$, mean wind speeds and mean wind power densities are determined.

Monthly mean wind speeds

The monthly mean wind velocity $\bar{v}$ and its standard deviation $\sigma$ are shown in Table 2 for the city of Ardabil for 2005-2010. The average monthly minimum and maximum standard deviations are observed to occur in June and March, with values 1.13 and 1.78 , respectively. The monthly variations in mean wind speed are shown in Fig. 3 for the 6-year period considered, and the minimum and maximum values of the monthly mean wind speeds are 
Table 3 Annual Weibull parameters and characteristic speeds at a $10 \mathrm{~m}$ height for the years studied in Ardabil

\begin{tabular}{llllll}
\hline Year & $\begin{array}{l}k \\
(-)\end{array}$ & $\begin{array}{l}c \\
(\mathrm{~m} / \mathrm{s})\end{array}$ & $\begin{array}{l}v_{\mathrm{mp}} \\
(\mathrm{m} / \mathrm{s})\end{array}$ & $\begin{array}{l}v_{\mathrm{op}} \\
(\mathrm{m} / \mathrm{s})\end{array}$ & $\begin{array}{l}\bar{v} \text { (measured) } \\
(\mathrm{m} / \mathrm{s})\end{array}$ \\
\hline 2005 & 2.83 & 3.89 & 3.33 & 4.70 & 3.44 \\
2006 & 2.98 & 4.22 & 3.70 & 5.01 & 3.77 \\
2007 & 2.69 & 4.25 & 3.58 & 5.23 & 3.78 \\
2008 & 2.88 & 3.68 & 3.17 & 4.42 & 3.28 \\
2009 & 2.89 & 4.41 & 3.81 & 5.29 & 3.93 \\
2010 & 2.95 & 4.55 & 3.95 & 5.42 & 4.08 \\
$2005-2010$ & 2.86 & 4.16 & 3.58 & 5.00 & 3.71 \\
\hline
\end{tabular}

found to be $2.09 \mathrm{~m} / \mathrm{s}$ (in November 2010) and $6.58 \mathrm{~m} / \mathrm{s}$ (in February 2006), respectively. Most of the average wind speeds range between 3.0 and $4.5 \mathrm{~m} / \mathrm{s}$.

Weibull distribution

Annual values of the Weibull shape and scale parameters, $k$ and $c$, are presented in Table 3 , as calculated with the formulas in Sect. 3.1. The yearly values of $k$ are observed to vary from 2.69 to 2.98 with a mean value of 2.86 , while those of $c$ vary from 3.68 to 4.55 , with a mean of 4.16 . The average annual variations of the observed and Weibull

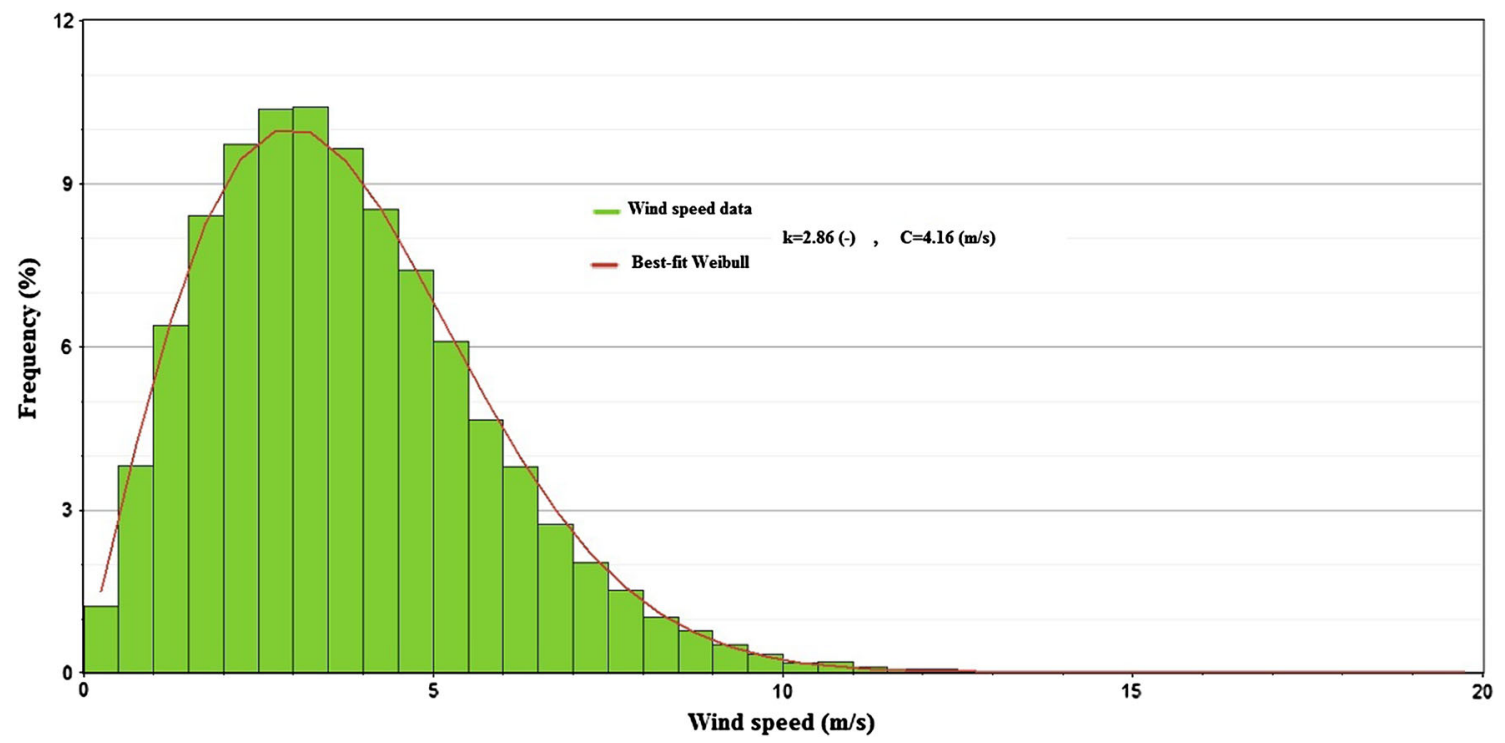

Fig. 4 Mean annual variation of observed and Weibull wind speed frequencies for Ardabil (2005-2010)

Table 4 Monthly mean Weibull parameters and characteristic speeds at a height of $10 \mathrm{~m}$ and wind power density and energy for Ardabil

\begin{tabular}{lllllllc}
\hline Month & $\begin{array}{l}k \\
(-)\end{array}$ & $\begin{array}{l}c \\
(\mathrm{~m} / \mathrm{s})\end{array}$ & $\begin{array}{l}v_{\mathrm{mp}} \\
(\mathrm{m} / \mathrm{s})\end{array}$ & $\begin{array}{l}v_{\mathrm{op}} \\
(\mathrm{m} / \mathrm{s})\end{array}$ & $\begin{array}{l}\bar{v}(\mathrm{measured}) \\
(\mathrm{m} / \mathrm{s})\end{array}$ & $\begin{array}{l}P / A \\
\left(\mathrm{~W} / \mathrm{m}^{2}\right)\end{array}$ & $\begin{array}{l}E / A \\
\left(\mathrm{kWh} / \mathrm{m}^{2} / \mathrm{month}\right)\end{array}$ \\
\hline January & 2.62 & 3.72 & 3.10 & 4.62 & 4.29 & 86.22 & 62.92 \\
February & 3.17 & 3.49 & 3.10 & 4.07 & 4.86 & 76.84 & 56.07 \\
March & 2.99 & 3.60 & 3.14 & 4.27 & 4.88 & 79.39 & 57.93 \\
April & 2.88 & 4.04 & 3.49 & 4.85 & 3.76 & 91.38 & 66.68 \\
May & 2.70 & 4.35 & 3.66 & 5.34 & 2.99 & 102.38 & 74.71 \\
June & 3.10 & 3.58 & 3.16 & 4.20 & 3.20 & 76.71 & 55.98 \\
July & 3.00 & 3.36 & 2.94 & 3.98 & 3.88 & 72.05 & 52.58 \\
August & 2.70 & 4.22 & 3.56 & 5.18 & 3.59 & 95.83 & 69.93 \\
September & 2.91 & 5.47 & 4.73 & 6.55 & 3.21 & 149.54 & 109.12 \\
October & 2.89 & 5.43 & 4.69 & 6.51 & 3.11 & 150.15 & 109.57 \\
November & 2.65 & 4.83 & 4.04 & 5.97 & 3.31 & 126.71 & 92.46 \\
December & 3.15 & 3.85 & 3.41 & 4.50 & 3.45 & 86.88 & 63.40 \\
\hline
\end{tabular}


Table 5 Weibull wind power and annual energy production for 2005-2010 for Ardabil

\begin{tabular}{lrl}
\hline Year & $\begin{array}{l}P / A \\
\left(\mathrm{~W} / \mathrm{m}^{2}\right)\end{array}$ & $\begin{array}{l}E / A \\
\left(\mathrm{kWh} / \mathrm{m}^{2} / \text { year }\right)\end{array}$ \\
\hline 2005 & 87.25 & 764.01 \\
2006 & 96.33 & 843.52 \\
2007 & 100.09 & 876.44 \\
2008 & 81.34 & 712.26 \\
2009 & 103.77 & 908.67 \\
2010 & 103.71 & 908.14 \\
Annual mean & 95.55 & 836.69 \\
\hline
\end{tabular}

wind speed frequencies for Ardabil are shown in Fig. 4. The percentage error between the Weibull wind speed frequencies and the observed frequencies is almost identical for various wind speeds.

Monthly Weibull parameters are listed in Table 4. The highest monthly value of the Weibull scale parameter is observed to be $5.47 \mathrm{~m} / \mathrm{s}$ (in September), while the Weibull shape parameter reaches a monthly low of 2.62 (in January) and a monthly high of 3.17 (in February).

Wind power density and energy

The wind power density and wind energy density, calculated with Eqs. 13 and 14, respectively, are presented for Ardabil in Table 5. The annual power density is found to vary between $81 \mathrm{~W} / \mathrm{m}^{2}$ in 2008 and $104 \mathrm{~W} / \mathrm{m}^{2}$ in 2009 , while the wind energy density (E/A) ranges from 712 to $909 \mathrm{kWh} / \mathrm{m}^{2} /$ year.

The monthly variation of the wind power density at a $10 \mathrm{~m}$ height is shown in Table 4. The highest monthly mean power densities are observed in October and September, with values 150.15 and 149.54 , respectively. Note that these values increase with increasing altitude and wind speed.

Ardabil is a fair to fairly good location in terms of wind generation potential, based on the following magnitudebased assessment categorization for the wind resource [27]:

Fair $\left(P / A<100 \mathrm{~W} / \mathrm{m}^{2}\right)$

Fairly good $\left(100 \mathrm{~W} / \mathrm{m}^{2} \leq P / A<300 \mathrm{~W} / \mathrm{m}^{2}\right)$

Good $\left(300 \mathrm{~W} / \mathrm{m}^{2} \leq P / A<700 \mathrm{~W} / \mathrm{m}^{2}\right)$

Very $\operatorname{good}\left(P / A \geq 700 \mathrm{~W} / \mathrm{m}^{2}\right)$

\section{Conclusions}

The wind speed and wind energy potential for the Iranian northwestern city of Ardabil are successfully investigated, using data measured at a height of $10 \mathrm{~m}$ aboveground level over a 6-year period. The wind energy potential of the location is studied based on the Weibull model, and monthly and annual wind speed variations were examined. The main results and conclusions from this study are as follows:

1. The monthly mean wind speed is between 2.09 and $6.58 \mathrm{~m} / \mathrm{s}$, while the annual mean wind speed ranges from 3.28 to $4.08 \mathrm{~m} / \mathrm{s}$.

2. The monthly mean value of the Weibull scale parameter is between 3.36 and $5.43 \mathrm{~m} / \mathrm{s}$, while the monthly mean value of shape parameter is between 2.62 and 3.17 .

3. October has the highest mean power density $\left(150.15 \mathrm{~W} / \mathrm{m}^{2}\right)$ and July has the lowest $\left(72.05 \mathrm{~W} / \mathrm{m}^{2}\right)$.

4. The maximum and minimum yearly mean wind energy densities are $712 \mathrm{kWh} / \mathrm{m}^{2}$ (in 2008) and $909 \mathrm{kWh} / \mathrm{m}^{2}$ (in 2009), respectively.

5. The data suggest that the wind potential of Ardabil is suitable for off-grid connections and could be acceptable for connecting to power grids.

Open Access This article is distributed under the terms of the Creative Commons Attribution License which permits any use, distribution, and reproduction in any medium, provided the original author(s) and the source are credited.

\section{References}

1. Meishen, Li, Xiamguo, Li: Investigation of wind characteristics and assessment of wind energy potential for Waterloo region, Canada. Energy Convers. Manag 46(18-19), 3014-3033 (2005)

2. Sahin, A.D.: Progress and recent trends in wind energy. Energy Combust. 30, 501-543 (2004)

3. Alijani, B., Ghohtoudi, M., Arabi, N.: Developing a climate model for Iran using GIS. Theor. Appl. Climatol. 92, 103-112 (2008)

4. Garrad, A.: Wind energy in Europe: a plan of action. Summary report of wind energy in Europe time for action. The European Wind Energy Association Press, Germany (1991)

5. Globalwind energycouncil (GWEC) Global wind statistics. Brussels, Belgium (2013)

6. Iranian Renewable Energy Organization (SUNA) Tehran, Iran. 2013. http://www.suna.org.ir/fa/wind/statistics. Accessed 08 Feb 2014

7. Blanchard, M., Desrochers, G.: Generation of autocorrelated wind speeds for energy conversion system studies. Sol. Energy 33(6), 571-579 (1984)

8. Conradsen, K., Nielsen, L.B., Prahm, L.P.: Review of Weibull statistics for estimation of wind speed distributions. Clim. Appl. Meteorol. 23, 1173-1183 (1984)

9. Cortis, R.B., Sigl, A.B., Klein, J.: Probabilities models of wind velocity magnitude and persistence. Sol. Energy 20, 483-493 (1978)

10. Sahin, B., Bilgili, M., Akilli, H.: The wind power potential of the eastern Mediterranean region of Turkey. Wind Eng. Ind. Aerodyn. 93(2), 171-183 (2005)

11. Keyhani, A., Ghasemi-Varnamkhasti, M., Khanali, M., Abbaszadeh, R.: An assessment of wind energy potential as a power generation source in the capital of Iran, Tehran. Energy 35(1), 188-201 (2010) 
12. Onat, N., Ersoz, S.: Analysis of wind climate and wind energy potential of regions in Turkey. Energy 36(1), 148-156 (2011)

13. Mostafaeipour, A., Sedaghat, A., Ghalishooyan, M., Dinpashoh, Y., Mirhosseini, M., Sefid, M.: Evaluation of wind energy potential as a power generation source for electricity production in Binalood, Iran. Renew. Energy 52, 222-229 (2013)

14. Mostafaeipour, A.: Feasibility study of offshore wind turbine installation in Iran compared with the world. Renew. Sustain. Energy Rev. 14, 1722-1743 (2010)

15. Ghobadian, B., Najafi, G.H., Rahimi, H., Yusaf, T.F.: Future of renewable energies in Iran. Renew. Sustain. Energy Rev. 13, 689-695 (2009)

16. Mostafaeipour, A., Mostafaeipour, N.: Renewable energy issues and electricity production in Middle East compared with Iran. Renew. Sustain. Energy Rev. 13, 1641-1645 (2009)

17. Mostafaeipour, A., Abarghooei, H.: Harnessing wind energy at Manjil area located in north of Iran. Renew. Sustain. Energy Rev. 12(6), 1758-1766 (2008)

18. Saeidi, D., Mirhosseini, M., Sedaghat, A., Mostafaeipour, A.: Feasibility study of wind energy potential in two provinces of Iran: North and South Khorasan. Renew. Sustain. Energy Rev. 15, 3558-3569 (2011)

19. Mostafaeipour, A., Sedaghat, A., Dehghan-Niri, A.A., Kalantar, V.: Wind energy feasibility study for city of Shahrbabak in Iran. Renew. Sustain. Energy. Rev. 15(6), 2545-2556 (2011)
20. Jie, W., Jianzhou, W., Dezhong, C.: Wind energy potential assessment for the site of Inner Mongolia in China. Renew. Sustain. Energy Rev. 21, 215-228 (2013)

21. From Wikipedia the free encyclopaedia, Wind power. http://en. wikipedia.org/wiki/Ardabil. Accessed 08 Feb 2014

22. Chang, T.J., Wu, Y.T., Hsu, H.Y., Chu, C.R., Liao, C.M.: Assessment of wind characteristics and wind turbine characteristics in Taiwan. Renew. Energy 28, 851-871 (2003)

23. Ouammi, A., Dagdougui, H., Sacile, R., Mimet, A.: Monthly and seasonal assessment of wind energy characteristics at four monitored locations in Liguria region (Italy). Renew. Sustain. Energy Rev. 14, 1959-1968 (2010)

24. Kwon, S.D.: Uncertainty analysis of wind energy potential assessment. Appl. Energy 87, 856-865 (2010)

25. Jamil, M., Parsa, S., Majidi, M.: Wind power statistics and evaluation of wind energy density. Renew. Energy 6, 623-628 (1995)

26. Celik, A.N.: Statistical analysis of wind power density based on the Weibull and Rayleigh models at the southern region of Turkey. Renew. Energy 29, 593-604 (2004)

27. Ambrosini, G., Benato, B., Garavaso, C., Botta, G., Cenerini, M., Comand, D.: Wind energy potential in Emilia Romagna, Italy. Wind Eng. Ind. Aerodyn. 39, 211-220 (1992) 